\title{
DISCRIMINATION AEROSOL FORM CLOUDS USING CATS-ISS LIDAR OBSERVATIONS BASED ON RANDOM FOREST AND SVM ALGORITHMS OVER THE EASTERN PART OF MIDDLE EAST
}

\author{
Foad Brakhasi ${ }^{1, *}$, Mohammad Hajeb ${ }^{1}$, Fatemeh Fouladinejad ${ }^{1}$ \\ ${ }^{1}$ Remote sensing and GIS Center, University of Shahid Beheshti, Tehran, Iran - brakhasi.f@gmail.com, m_hajeb@ @bu.ac.ir, \\ f.fooladinezhad@gmail.com
}

KEYWORDS: Aerosol, Cloud, CATS-ISS, Classification, Random Forest, SVM, Machine Learning

\begin{abstract}
:
Aerosols and Clouds play an important role in the Earth's environment, climate change and climate models. The Cloud-Aerosol Transport System (CATS) as a lidar remote sensing instrument, from the International Space Station (ISS), provides range-resolved profile measurements of atmospheric aerosols and clouds. Discrimination aerosols from clouds have always been a challenges task in the classification of space-born lidars. In this study, two algorithms including Random Forest (RF) and Support Vector Machine (SVM) were used to tackle the problem in a nighttime lidar data from 18 October 2016 which passes form the western part of Iran. The procedure includes 3 stages preprocessing (improving the signal to noise, generating features, taking training sample), classification (implementing RF and SVM), and postprocessing (correcting misleading classification). Finally, the result of classifications of the two algorithms (RF-SVM) were compared against ground truth samples and Vertical Feature Mask (VFM) of CATS product indicated 0.96-0.94 and 0.88-0.88 respectively. Also, it should be mentioned that a kappa accuracy 0.88 was acquired when we compared VFM against our ground truth samples. Moreover, a visual comparison with Moderate Resolution Imaging Spectroradiometer (MODIS) AOD and RGB products demonstrating that clouds and aerosol can be well detected and discriminated. The experimental results elucidated that the proposed method for classification of space borne lidar observation leads to higher accuracy compared to PDFs based algorithms.
\end{abstract}

\section{INTRODUCTION}

Aerosols are suspended particles (liquid or soil) in the atmosphere (Wong et al., 2013) which have a different physical, chemical and light scattering characteristic and so they have a high variability in time and space (IPCC, 2001; Murari et al., 2015; Tomasi et al., 2015). These particles are produced as the result of natural activities such as volcanoes, storms as well as human activities such as burning fossil fuels and traffic are produced (Gong and Ma, 2012; Kokkalis et al., 2012; Wiltshire, 2011; Zhu et al., 2016). Aerosol phenomenon and suspended particles in the atmosphere as one of the important sources of uncertainties in climate models result in reduced accuracy in remote sensing and its difference with ground-based measurements. Moreover, aerosols play an important role in cloud formation, chemical processes and precipitation (Kumar et al., 2018; Lin et al., 2014; Petiot, 2012; Stocker, 2014), great potential to change earth climate balance (Kumar et al., 2015), and negative effect on human health by affecting on air quality and traffic (Brunekreef and Holgate, 2002; Darquenne, 2012; Kulkarni et al., 2011).

There are several methods for studying aerosols including in-situ measurements, models and remote sensing-based techniques (Brakhasi et al., 2018). The in-situ measurements are performed discretely and point at ground stations, and are not capable of showing a significant change in the temporal and spatial extent of aerosols. Aerosol Models (Geng et al., 2015; Nowottnick et al., 2015; Prijith et al., 2016; Vijayakumar et al., 2016) often have a lot of inputs and the results of such models are also associated with uncertainty (Yu et al., 2015). Remote sensing technology is knowable as one of the promising methods in studying different events of climate and atmospheric simultaneously at the global scale (Kokhanovsky, 2013; Smith et al., 2019). Passive sensors such as MODIS as a widely used technique in studying of aerosols are constraint by daytime and data acquisition in the cloudy condition. Concerning the necessity of vertical distribution study of aerosols to comprehensive understanding of aerosols (Nabavi et al., 2016), such instruments cannot measure vertical distribution of aerosols (Kar et al., 2015). However, state-of-the-art space borne lidars including Ice, Cloud, and land Elevation (ICESat- launched at 2003), Cloud-Aerosol Lidar and Infrared Pathfinder (CALIPSO- launched at 2006), The CloudAerosol Transport System (CATS- launched at 2015), the Ice, Cloud, and land Elevation Satellite-2 (ICESat-2- launched at 2018) as well as future mission Earth Cloud Aerosol and Radiation Explorer (EarthCARE) and Aerosol-CloudEcosystems (ACE) have revolutionized the studying of atmosphere and investigating the vertical distribution of aerosol and clouds (Fueglistaler et al., 2009; Tomasi et al., 2015). The active instrument CALIOP on the CALIPSO satellite and the Cloud-Aerosol Transport System (CATS) instrument on the International Space Station (ISS) are the two more applicable devices to measure vertical profiles of aerosol and clouds. Compare to CALIOP, CATS instrument located an altitude of about $405 \mathrm{~km}$ and it has depolarization measurement at $1064 \mathrm{~nm}$. Moreover, the CATS-ISS orbit is particularly suited to aerosol measurement because the 51-degree inclination of the orbit puts ISS tracks over and along primary aerosol transport paths. Generally numerous studies including classification and detection (Brakhasi et al., 2018; Chen et al., 2010; Gong and Ma, 2012; Kar et al., 2015; Liu et al., 2015, 2014, 2009; Lu et al., 2011; Ma et al., 2011; Ma and Gong, 2012; Naeger et al., 2013; Omar et al., 2009; Vaughan et al., 2009), have been done using space borne lidar data. It should be mentioned that classification and discrimination of aerosols from clouds as the most important 
and challenges step has been emphasized. Previous studies used different methods including Probability Density Functions (PDFs) based (Chen et al., 2010; Gong and Ma, 2012; Kar et al., 2015; Liu et al., 2015, 2014, 2009, 2004; Naeger et al., 2013; Vaughan et al., 2009; Liu et al., 2019) and machine learning (Brakhasi et al., 2018; Ma and Gong, 2012; Ma et al., 2011) which has their own advantages and disadvantages. It is really worth mentioning that almost in all of the previous works in the classification of space bourn lidars, the challenges part is discrimination thin aerosol from clouds or mixed aerosols and clouds. Unlike machine learning methods, the PDFs based algorithms lead to coarse classification which cannot fully represent spatial distribution of aerosols and clouds. Separating clouds mixed with aerosols and thin aerosol as discussed is another challenge for these algorithms. Considering discrimination aerosol form clouds in spaceborne lidar observation, the result has shown that support vector machine (SVM) as a machine learning algorithm compared to methods based on probability distribution function could lead to better results for the classification of aerosols and cloud (Brakhasi et al., 2018; Ma et al., 2011). Additionally, the potential of these algorithms, especially random forest (RF) classifier as an ensemble learning technique for processing satellite images for various application is receiving highlighted interest (Ahmed et al., 2015; Chen et al., 2014; Hudak et al., 2008; RodriguezGaliano et al., 2012; Thanh Noi and Kappas, 2018). However, it has not been utilized in processing of space born lidars as we know. Therefore, the main objective of this research is to test and demonstrate the effectiveness of RF and SVM machine models for discriminating aerosols from clouds using CATS-ISS lidar observation. Also, we present an almost novel method for taking training samples in CATS-ISS lidar data.

\section{METHODOLOGY AND STUDY AREA}

In this research, the two machine learning methods including Random Forest (RF) and Support Vector Machine (SVM) is applied on the CATS-ISS lidar data. The RF and SVM are nonparametric models for classification or regression that utilize training samples in order to classify the data. The RF algorithm fits multiple decision trees and combines the predictions from all of the trees. It iteratively and randomly samples the data and variables to produce a large group, or forest, of classification and regression trees (CART) (Breiman, 2001). However, SVM define a hyperplane in the feature space based on training samples. In fact, after finding the support vectors, the hyper plan is fitted (Cortes and Vapnik, 1995). The overpass is related to 18 October 2016 which passes from the western part of Iran and north of Iraq and eastern part of Syria. These regions have been imposed against strong dust storms. Also, for several week at the summer of 2016, ISIS has been burning oil wells south of the Iraqi city of Mosul, sending toxic plumes into the atmosphere which is observed by CATS-ISS at the aforementioned date (Fig. 1). Thus, the purpose of the implementation these algorithms is classifying scene lidar data into feature regions including aerosol and cloud and Non- feature regions containing clean air, surface, subsurface, totally attenuated. However, more attention is paid to atmospheric feature regions because of higher importance in the atmospheric studies and climate models.

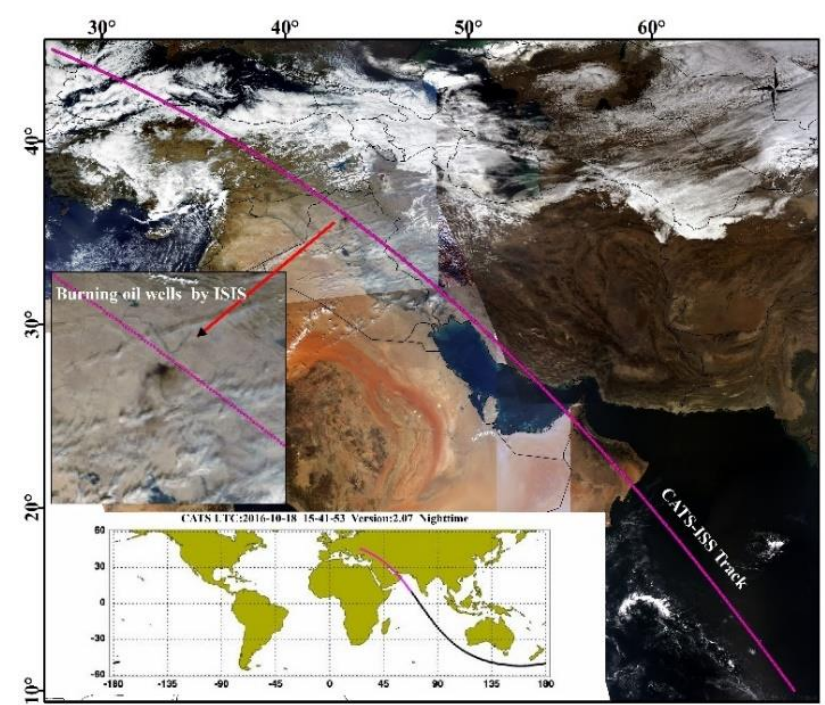

Figure 1. The study overpass of CATS-ISS

Research is carried out in three main stages. Flowchart is shown in the Fig.2: 

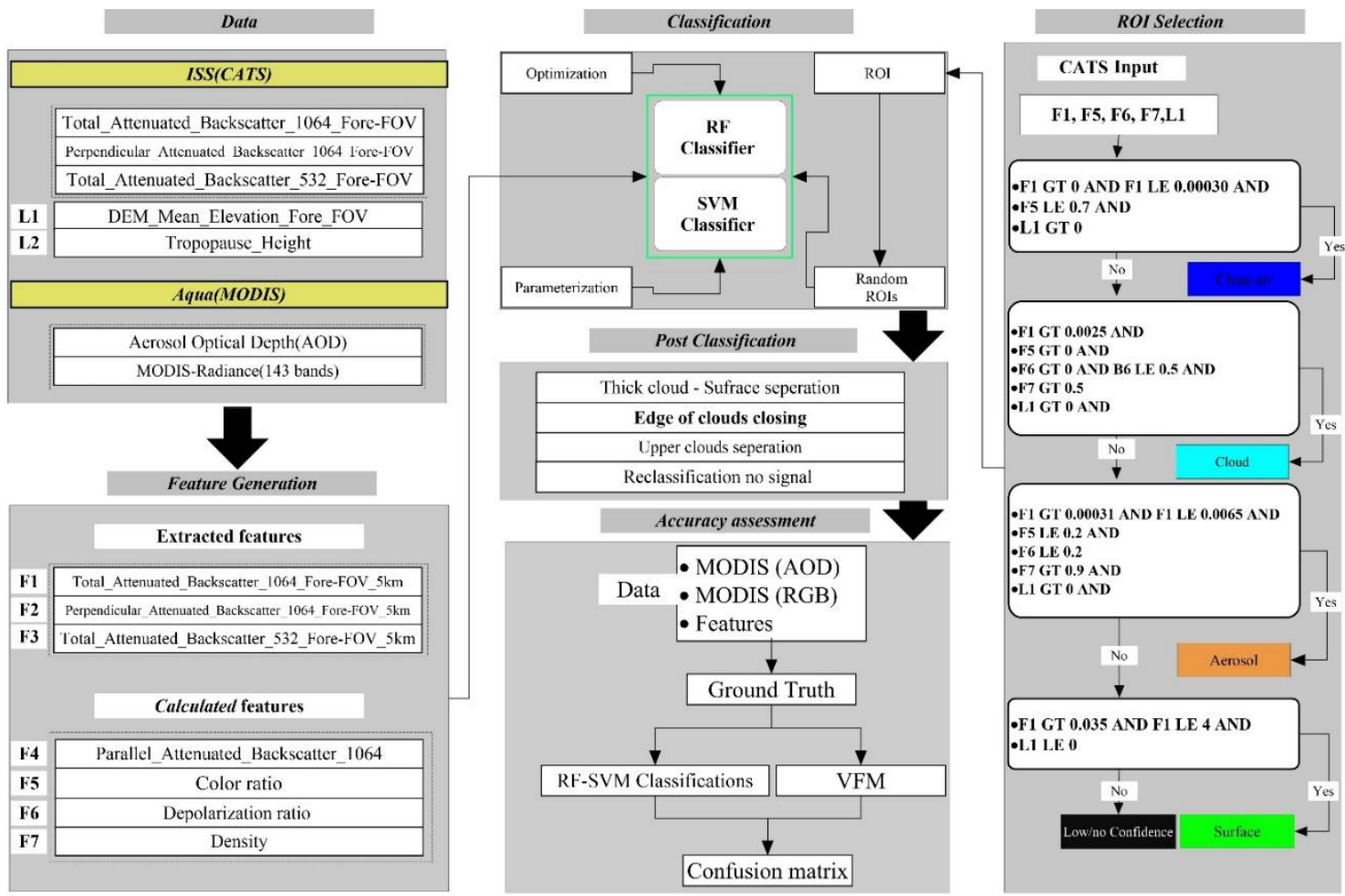

Figure 2. Flowchart of ground truth selection and RF-SVM classifications

\section{IMPLEMENTATION AND EXPERIMENTAL \\ RESULTS}

\subsection{Preprocessing and Feature Generation}

At this stage 3 features including total attenuated backscatter at $1064 \mathrm{~nm}\left(\beta_{1064, \perp}\right)$ (Fig.3 (c)), perpendicular attenuated backscatter at $1064 \mathrm{~nm}\left(\beta_{1064, \perp}\right)$, and total attenuated backscatter at $532 \mathrm{~nm}\left(\beta_{532}\right)$, are extracted by horizontal averaging of 15 profile in order to improving signal to noise ratio. In the following, 4 other features including parallel attenuated backscatter at $1064 \mathrm{~nm}\left(\beta_{1064, \|}\right)$, color ratio $(\chi)$, depolarization ratio $(\delta)$ based on equations 1, 2 and 3(Hostetler et al., 2006), and particle density (PD) are calculated.

$$
\begin{aligned}
& \beta_{1064, \|}=\beta_{1064}-\beta_{1064, \perp} \\
& \chi=\frac{\beta_{1064}}{\beta_{532}} \\
& \delta=\frac{\beta_{1064, \perp}}{\beta_{1064, \|}}
\end{aligned}
$$

Color ratio are related to the size of the particles and value 1 or less is related to aerosols particle and value greater than 1 is related to clouds (Fig.3 (b)), while depolarization ratio is an index of shape of the particles. Smoke has a spherical and regular shape and has a lower depolarization value ((Fig.3 (a))) in comparison to dust and ice crystal with irregular shape (Hostetler et al., 2006; Yu et al., 2015).

It is worth mentioning here that previous work (Brakhasi et al., 2018) has been shown that PD has a great impact on the classification accuracy. Thus, PD is produced by proper thresholding 0.0003 on the $\beta_{1064}$ and then applying $3 * 3$ kernel.
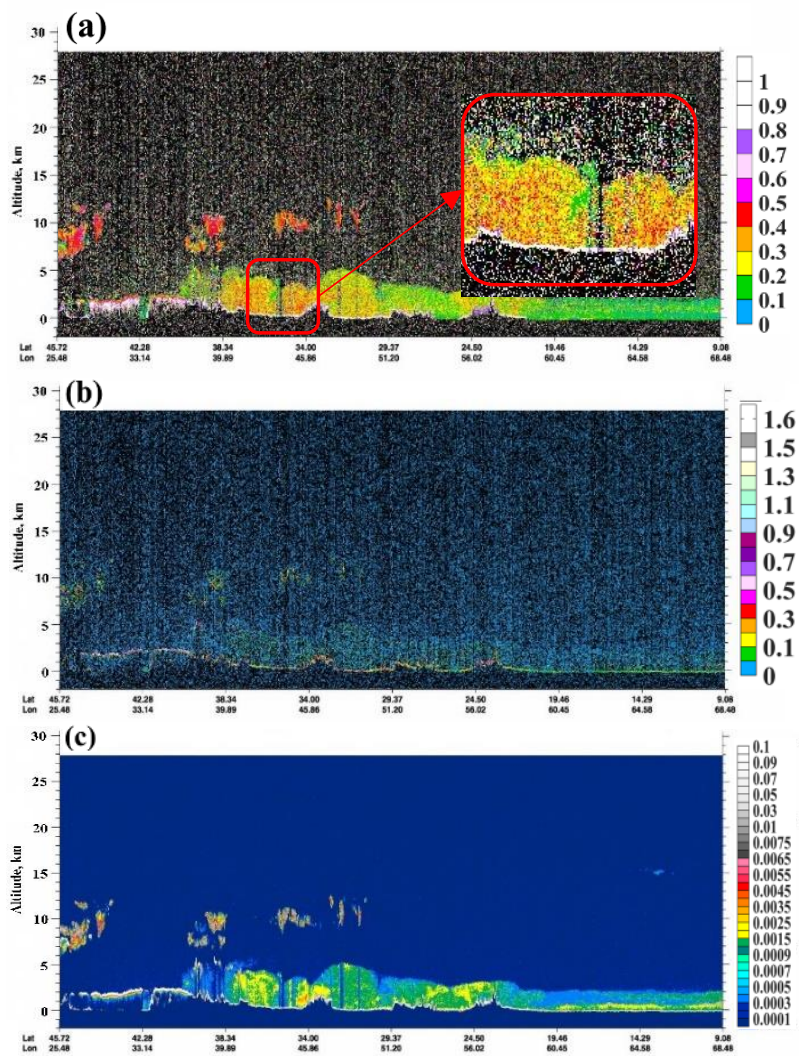

Figure 3. Depolarization ratio (a), color ratio (b) and total attenuated backscatter at $1064 \mathrm{~nm}$ (c). Smoke steams form burning oil wells by ISIS has a lower DR and higher backscatter intensity.

\subsection{Classifications}

The first and significant step for implementation RF and SVM classifier is generating training samples. However, producing these samples in lidar data is not as easy as optic data due to 
complexity in the interpretation of lidar observations (Khoshelham et al., 2013). Besides, visually taking training samples for phenomenon like aerosol and cloud particles which have a constant microphysical characteristic is not advised. Thus, training samples were selected automatically based on ROI selection algorithm (Fig.2 and 4) and in total 600 samples in a previous work with some modifications (Brakhasi et al., 2018). Moreover, by parametrization and optimization of RF and SVM classifiers, the scene lidar data classified. It is noticed that the number of 100 trees for RF is selected. Also, the penalty parameter $\mathrm{c}$ and $\mathrm{g}$ were optimized based on a gird search using a 3 -fold cross validation. The initial result of this stage is shown in Fig.5 (a).

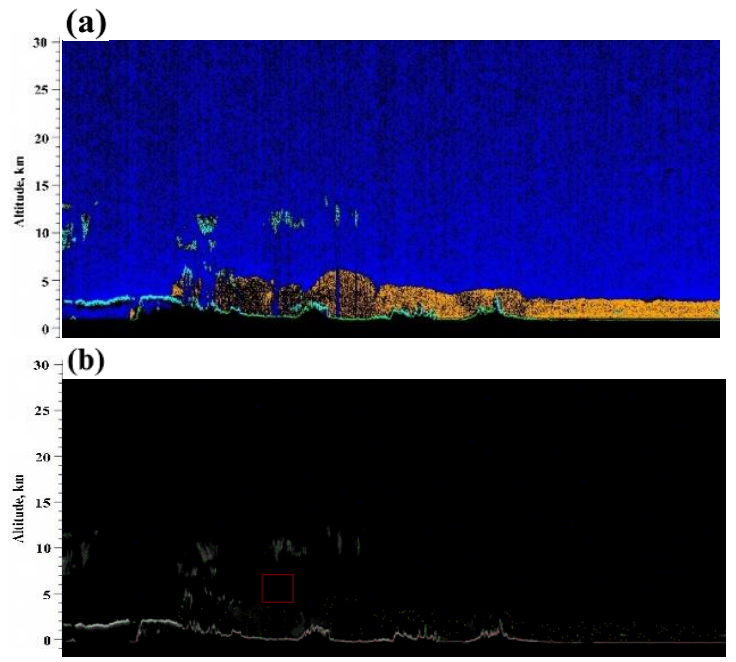

Figure 4. ROI algorithm selection (a), result of random selection $(\mathrm{b})$

\subsection{Post processing}

Due to some misclassification in the initial RF and SVM classification Fig.6 (a) in this step we need to correct them based on a knowledge-based approach and previous works. These misclassifications along with the solutions for eliminate them are presented as follows: (a) The surface and thick clouds have a similar backscatter intensity and so thick clouds classified inaccurately as surface; by using surface elevation (SE) layer as an ancillary data form level 1 CATS-ISS, the surface class pixels higher than SE layer returned to cloud class. (b) The margin of clouds usually behaves link aerosols and so classified mistakenly in place of clouds; selecting mathematical morphology such misclassification is tackled. (c) High clouds like cirrus and stratospheric clouds due to strong wind spared horizontally and behave like aerosols at 532 and $1064 \mathrm{~nm}$; so, by using tropopause high layer, the misclassifications were corrected. Also, it is worth mentioning that laser pulses at 532 and $1064 \mathrm{~nm}$ penetrate form thin clouds, but passes a little in the thick clouds, so in such situation the surface cannot be captured by laser; thus, by take advantage of uncaptured surface, the pixels under thick clouds labeled totally attenuated. Thus, the final classification result including 6 class clean air, cloud, aerosol, surface, subsurface and totally attenuated was achieved Fig.6 (c and d).

\section{ACCURACY ASSESSMENT}

The results of classifications were compared visually against MODIS AOD (MYD04_3 K) and true color (MYD02HKM) (Fig 5 and Fig 1 respectively), and quantitatively against ground testing samples and also CALIPSO vertical feature mask production (VFM). In this comparison, more attention is paid to feature region (cloud and aerosol).

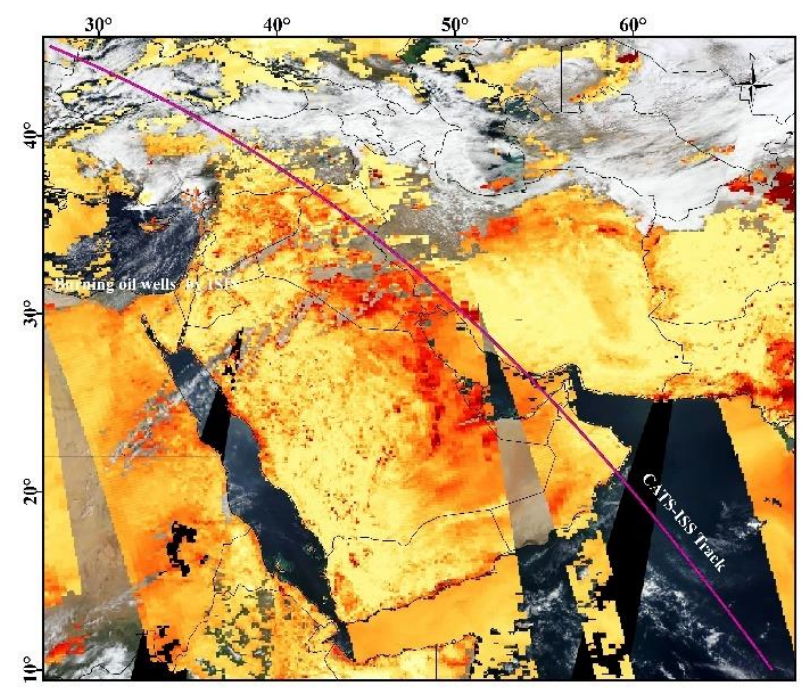

Figure 5. MODIS-AOD along with ISS-CATS orbit at 18 October 2016

In visually comparison, we found that both FR and SVM classification show a good general agreement when it compared with MODIS-AOD and reflectance. Also, it should be mentioned that in this case study, the aerosols including smoke and dust mixed with clouds at some location (usually upper latitude) and the results of the algorithms is promising at detection smoke embedded in the dust and dust embedded in the clouds. Additionally, as can be seen from MODIS RGB images, the discrimination of clouds from aerosols around the top of mountain by RF and SVM algorithms is overweight the algorithms based on PDFs. The quantitatively assessment is including two parts. At first, the results were compared with VFM to better understand the performance machine classifiers and PDFs based algorithms. In this comparison, the classifications (RF or SVM) were compared pixel by pixel with VFM. The kappa accuracy between RF and SVM classifications with VFM products were obtained 0.88 and 0.88 respectively, which shows high general agreement. Moreover, by visual inspection from MODIS (AOD and reflectance) and CATS lidar data, the ground truth polygons were taken. Final ground truth samples were selected randomly in the total number of 40800 . The comparison RF and SVM classifications, and VFM product against ground samples shown the kappa accuracy 0.96, 0.94 and 0.88 respectively. Additionally, by pay more attention to feature regions, the conditional kappa of clear air, cloud and aerosol for RF result (0.97, 0.92 and 0.98 respectively), SVM result (0.97, 0.93 and 0.98$)$ and VFM $(0.95,0.75$ and 0.93$)$ were calculated.

\section{CONCLUSIONS}

This study presents performance of two machine learning 

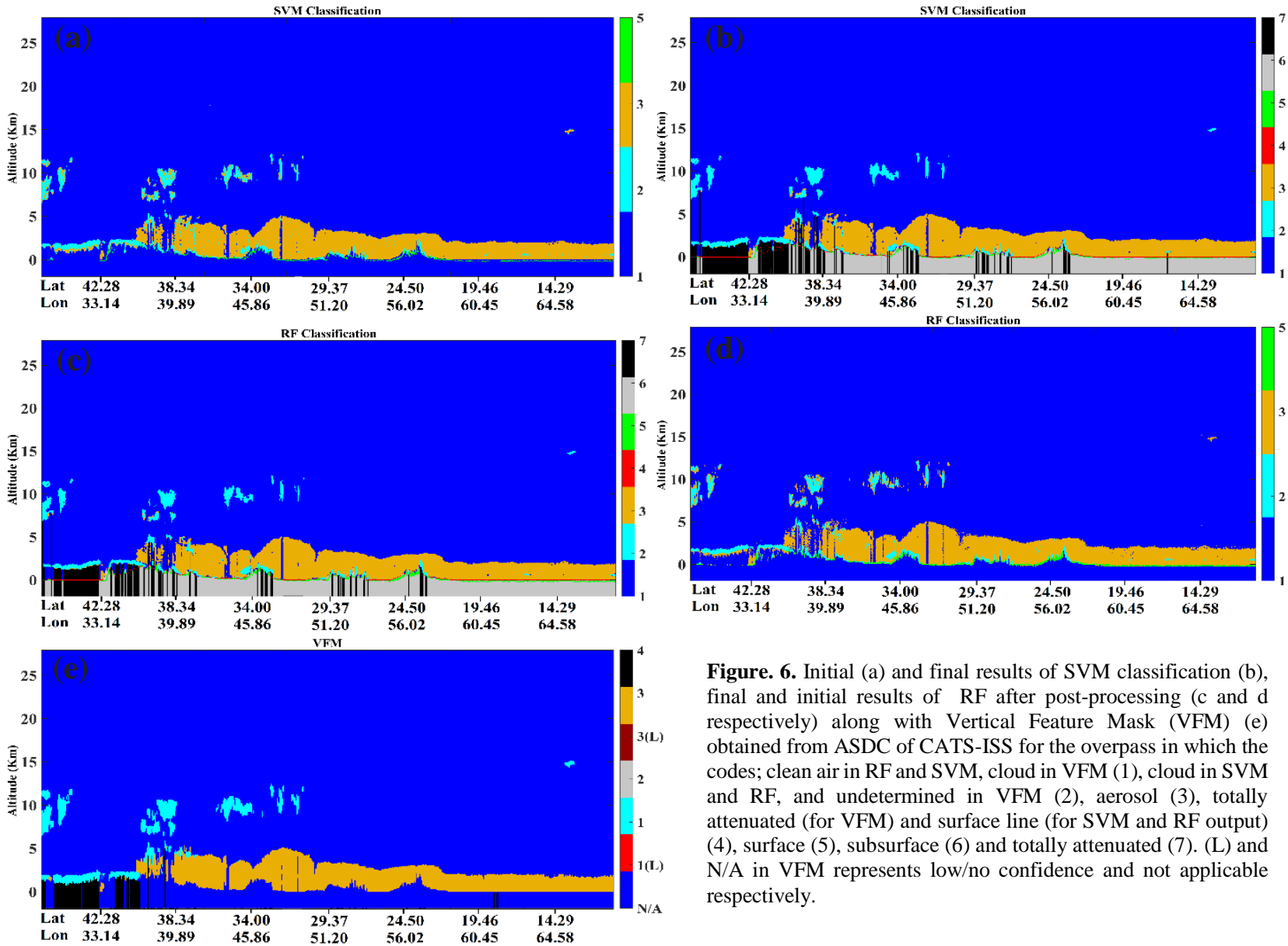

Figure. 6. Initial (a) and final results of SVM classification (b), final and initial results of RF after post-processing (c and $d$ respectively) along with Vertical Feature Mask (VFM) (e) obtained from ASDC of CATS-ISS for the overpass in which the codes; clean air in RF and SVM, cloud in VFM (1), cloud in SVM and RF, and undetermined in VFM (2), aerosol (3), totally attenuated (for VFM) and surface line (for SVM and RF output) (4), surface (5), subsurface (6) and totally attenuated (7). (L) and N/A in VFM represents low/no confidence and not applicable respectively.

algorithms, RF and SVM, on CAST-ISS lidar observation. This study presents performance of two machine learning algorithms, RF and SVM, on CAST-ISS lidar observation. This is the first study to classify CATS lidar data using the aforementioned algorithms in the overpass at eastern Middle East. For the detection and discrimination of the aerosols and clouds, RF and SVM algorithms using automatically generated training samples was successfully applied to the space borne lidar observation. However, current space bourn lidar classification method for producing VFM product has some limitations with respect to mixed aerosols and clouds. The advantage of machine learning approaches is that they are more compatible with the very complex structure of the atmosphere due to its high spatialtemporal variability and also the very complex interaction of atmospheric particles of different sizes and shapes with laser pulses. Thus, they lead to a finer classification which is more compatible with aerosols and climate modeling in comparison with VFM product which leads to a coarse pattern. So, a scene lidar data of CATS instrument at 18 October 2016 which passes from locations with mixed dust and clouds and smoke originating from burning oil wells by ISIS, were preprocessed, classified and postprocessed. It should be mentioned that training samples were selected automatically based on microphysical characteristics of aerosols and clouds. Moreover, the total number of 7 features were used in the classification including the two features of total attenuated backscatter at 1064 and 532, color ratio, depolarization ratio, particle density and the two features of parallel and perpendicular attenuated backscatter at 1064 .

\section{REFERENCES}

Ahmed, O.S., Franklin, S.E., Wulder, M.A., White, J.C., 2015. Characterizing stand-level forest canopy cover and height using Landsat time series, samples of airborne LiDAR, and the Random Forest algorithm. ISPRS J. Photogramm. Remote Sens. 101, 89101.

Brakhasi, F., Matkan, A., Hajeb, M., Khoshelham, K., 2018. Atmospheric scene classification using CALIPSO spaceborne lidar measurements in the Middle East and North Africa (MENA), and India. Int. J. Appl. Earth Obs. Geoinf. 73, 721-735. https://doi.org/10.1016/j.jag.2018.07.017

Breiman, L., 2001. Random forests. Mach. Learn. 45, 5-32.

Brunekreef, B., Holgate, S.T., 2002. Air pollution and health. Lancet 360, 1233-1242.

Chen, B., Huang, J., Minnis, P., Hu, Y., Yi, Y., Liu, Z., Zhang, D., Wang, X., 2010. Detection of dust aerosol by combining CALIPSO

active lidar and passive IIR measurements. Atmos. Chem. Phys. 10, 4241-4251.

Chen, W., Li, X., Wang, Y., Chen, G., Liu, S., 2014. Forested landslide detection using LiDAR data and the random forest algorithm: A case study of the Three Gorges, China. Remote Sens. Environ. $152,291-301$

Cortes, C., Vapnik, V., 1995. Support-vector networks Machine learning (pp. 237-297), Vol. 20.

Darquenne, C., 2012. Aerosol deposition in health and disease. J. Aerosol Med. Pulm. Drug Deliv. 25, 140-147.

Fueglistaler, S., Dessler, A.E., Dunkerton, T.J., Folkins, I., Fu, Q., Mote, P.W., 2009. TROPICAL TROPOPAUSE LAYER 1-31. https://doi.org/10.1029/2008RG000267.1.INTRODUCTION

Geng, G., Zhang, Q., Martin, R. V, van Donkelaar, A., Huo, H., Che, H., Lin, J., He, K., 2015. Estimating long-term PM2. 5 concentrations in China using satellite-based aerosol optical depth and a chemical transport model. Remote Sens. Environ. 166, 262-270. 
Gong, W., Ma, Y., 2012. Retrieval and analysis of aerosol optical characteristics in Hubei Province, China, based on CALIPSO. Int J. Remote Sens. 33, 3252-3267.

Hostetler, C.A., Liu, Z., Reagan, J., Vaughan, M., Winker, D., Osborn, M., Hunt, W.H., Powell, K.A., Trepte, C., 2006. CALIOP algorithm theoretical basis document, calibration and level 1 data products. Cloud-Aerosol Lidar Infrared Pathfind. Satell. Obs. PCSCI-201 1-66.

Hudak, A.T., Crookston, N.L., Evans, J.S., Hall, D.E., Falkowski, M.J., 2008. Nearest neighbor imputation of species-level, plot-scale forest structure attributes from LiDAR data. Remote Sens. Environ. 112, 2232-2245

IPCC, 2001. Climate change 2001 IPCC third assessment report. Intergovernamental Panel Clim. Chang. Geneva, IPCC Secr.

Kar, J., Vaughan, M.A., Liu, Z., Omar, A.H., Trepte, C.R., Tackett, J., Fairlie, T.D., Kowch, R., 2015. Detection of pollution outflow from Mexico City using CALIPSO lidar measurements. Remote Sens. Environ. 169, 205-211.

Khoshelham, K., Elberink, S.O., Xu, S., 2013. Segment-based classification of damaged building roofs in aerial laser scanning data. IEEE Geosci. Remote Sens. Lett. 10, 1258-1262.

Kokhanovsky, A.A., 2013. Remote sensing of atmospheric aerosol using spaceborne optical observations. Earth Sci. Rev. 116, 95-108. https://doi.org/10.1016/j.earscirev.2012.10.008

Kokkalis, P., Mamouri, R.E., Todua, M., Didebulidze, G.G., Papayannis, A., Amiridis, V., Basart, S., Pérez, C., Baldasano, J.M., 2012. Ground-, satellite-and simulation-based analysis of a strong dust event over Abastumani, Georgia, during May 2009. Int. J. Remote Sens. 33, 4886-4901

Kulkarni, P., Baron, P.A., Willeke, K., 2011. Aerosol measurement: principles, techniques, and applications. John Wiley \& Sons.

Kumar, A., Singh, N., Solanki, R., 2018. Evaluation and utilization of MODIS and CALIPSO aerosol retrievals over a complex terrain in Himalaya. Remote Sens. Environ. 206, 139-155. https://doi.org/10.1016/j.rse.2017.12.019

Kumar, M., Tiwari, S., Murari, V., Singh, A.K., Banerjee, T., 2015. Wintertime characteristics of aerosols at middle Indo-Gangetic Plain: Impacts of regional meteorology and long range transport. Atmos. Environ. 104, 162-175.

Lin, N., Sayer, A.M., Wang, S., Loftus, A.M., Hsiao, T., Sheu, G., Hsu, N.C., Tsay, S., Chantara, S., 2014. Interactions between biomassburning aerosols and clouds over Southeast Asia : Current status , challenges, and perspectives. Environ. Pollut. 195, 292-307. https://doi.org/10.1016/j.envpol.2014.06.036

Liu, D., Yang, Y., Zhang, Y., Cheng, Z., Wang, Z., Luo, J., Su, L., Yang, L., Shen, Y., Bai, J., 2015. Pattern recognition model for aerosol classification with atmospheric backscatter lidars: principles and simulations. J. Appl. Remote Sens. 9, 96006.

Liu, J., Chen, B., Huang, J., 2014. Discrimination and validation of clouds and dust aerosol layers over the Sahara desert with combined CALIOP and IIR measurements. J. Meteorol. Res. 28, 185-198.

Liu, Z., Vaughan, M., Winker, D., Kittaka, C., Getzewich, B., Kuehn, R., Omar, A., Powell, K., Trepte, C., Hostetler, C., 2009. The CALIPSO lidar cloud and aerosol discrimination: Version 2 algorithm and initial assessment of performance. J. Atmos. Ocean. Technol. 26, 1198-1213.

Liu, Z., Vaughan, M.A., Winker, D.M., Hostetler, C.A., Poole, L.R., Hlavka, D., Hart, W., McGill, M., 2004. Use of probability distribution functions for discriminating between cloud and aerosol in lidar backscatter data. J. Geophys. Res. Atmos. 109.

Lu, X., Jiang, Y., Zhang, X., Wang, X., Spinelli, N., 2011. Twowavelength lidar inversion algorithm for determination of aerosol extinction-to-backscatter ratio and its application to CALIPSO lidar measurements. J. Quant. Spectrosc. Radiat. Transf. 112, 320-328.

Ma, Y., Gong, W., 2012. Evaluating the performance of SVM in dust aerosol discrimination and testing its ability in an extended area. IEEE J. Sel. Top. Appl. Earth Obs. Remote Sens. 5, 1849-1858.

Ma, Y., Gong, W., Wang, P., Hu, X., 2011. New dust aerosol identification method for spaceborne lidar measurements. J. Quant. Spectrosc. Radiat. Transf. 112, 338-345.

Murari, V., Kumar, M., Barman, S.C., Banerjee, T., 2015. Temporal variability of MODIS aerosol optical depth and chemical characterization of airborne particulates in Varanasi, India.
Environ. Sci. Pollut. Res. 22, 1329-1343.

Nabavi, S.O., Haimberger, L., Samimi, C., 2016. Climatology of dust distribution over West Asia from homogenized remote sensing data. Aeolian Res. 21, 93-107.

Naeger, A.R., Christopher, S.A., Ferrare, R., Liu, Z., 2013. A new technique using infrared satellite measurements to improve the accuracy of the CALIPSO cloud-aerosol discrimination method. IEEE Trans. Geosci. Remote Sens. 51, 642-653.

Nowottnick, E.P., Colarco, P.R., Welton, E.J., Da Silva, A., 2015. Use of the CALIOP vertical feature mask for evaluating global aerosol models. Atmos. Meas. Tech. 8, 3647-3669.

Omar, A.H., Winker, D.M., Vaughan, M.A., Hu, Y., Trepte, C.R., Ferrare, R.A., Lee, K.-P., Hostetler, C.A., Kittaka, C., Rogers, R.R., 2009. The CALIPSO Automated Aerosol Classification and Lidar Ratio Selection Algorithm. J. Atmos. Ocean. Technol. 26, 1994-2014. https://doi.org/10.1175/2009JTECHA1231.1

Petiot, S., 2012. Use of CALIOP satellite data to explore the distribution and sources of organic aerosols in the troposphere.

Prijith, S.S., Babu, S.S., Lakshmi, N.B., Satheesh, S.K., Moorthy, K.K., 2016. Meridional gradients in aerosol vertical distribution over Indian Mainland: Observations and model simulations. Atmos. Environ. 125, 337-345.

Rodriguez-Galiano, V.F., Ghimire, B., Rogan, J., Chica-Olmo, M., Rigol-Sanchez, J.P., 2012. An assessment of the effectiveness of a random forest classifier for land-cover classification. ISPRS J. Photogramm. Remote Sens. 67, 93-104.

Smith, V., Portillo-quintero, C., Sanchez-azofeifa, A., Hernandezstefanoni, J.L., 2019. Assessing the accuracy of detected breaks in Landsat time series as predictors of small scale deforestation in tropical dry forests of Mexico and Costa Rica. Remote Sens. Environ. 221, 707-721. https://doi.org/10.1016/j.rse.2018.12.020

Stocker, T., 2014. Climate change 2013: the physical science basis: Working Group I contribution to the Fifth assessment report of the Intergovernmental Panel on Climate Change. Cambridge University Press.

Thanh Noi, P., Kappas, M., 2018. Comparison of random forest, knearest neighbor, and support vector machine classifiers for land cover classification using Sentinel-2 imagery. Sensors 18, 18

Tomasi, C., Kokhanovsky, A.A., Lupi, A., Ritter, C., Smirnov, A., Neill, N.T.O., Stone, R.S., Holben, B.N., Nyeki, S., Wehrli, C., Stohl, A., Mazzola, M., Lanconelli, C., Vitale, V., Stebel, K., Aaltonen, V., Leeuw, G. De, Rodriguez, E., Herber, A.B., Radionov, V.F., Zielinski, T., Petelski, T., Sakerin, S.M., Kabanov, D.M., Xue, Y., Mei, L., Istomina, L., Wagener, R., Mcarthur, B., Sobolewski, P.S., Kivi, R., Courcoux, Y., Larouche, P., Broccardo, S., Piketh, S.J., 2015. Aerosol remote sensing in polar regions. Earth Sci. Rev. 140

108-157. https://doi.org/10.1016/j.earscirev.2014.11.001

Vaughan, M.A., Powell, K.A., Winker, D.M., Hostetler, C.A., Kuehn, R.E., Hunt, W.H., Getzewich, B.J., Young, S.A., Liu, Z., McGill, M.J., Aeronautics, N., Aeronautics, N., 2009. Fully Automated Detection of Cloud and Aerosol Layers in the CALIPSO Lidar Measurements. J. Atmos. Ocean. Technol. 26, 2034-2050. https://doi.org/10.1175/2009JTECHA1228.1

Vijayakumar, K., Devara, P.C.S., Rao, S.V.B., Jayasankar, C.K., 2016. Dust aerosol characterization and transport features based on combined ground-based, satellite and model-simulated data. Aeolian Res. 21, 75-85.

Wiltshire, B., 2011. Remote sensing of atmospheric aerosol distributions using supervised texture classification. University of Bath.

Wong, M.S., Shahzad, M.I., Nichol, J.E., Lee, K.H., Chan, P.W., 2013 Validation of MODIS, MISR, OMI, and CALIPSO aerosol optical thickness using ground-based sunphotometers in Hong Kong. Int. J. Remote Sens. 34, 897-918.

Yu, H., Chin, M., Bian, H., Yuan, T., Prospero, J.M., Omar, A.H., Remer, L.A., Winker, D.M., Yang, Y., Zhang, Y., 2015. Quantification of trans-Atlantic dust transport from seven-year (2007-2013) record of CALIPSO lidar measurements. Remote Sens. Environ. $159,232-249$

Zhu, J., Xia, X., Che, H., Wang, J., Zhang, J., Duan, Y., 2016. Study of aerosol optical properties at Kunming in southwest China and long-range transport of biomass burning aerosols from North Burma. Atmos. Res. 169, 237-247. 